\title{
Kanola (Brassica Napus L.) Çeşitlerinin Azot Etkinliğinin Karşılaştırılması
}

\section{Comparison of Nitrogen Efficiency of Canola (Brassica napus L.) Cultivars}

\section{ÖZET}

$\mathrm{Bu}$ çalışmanın amacı kanola çeşitlerinin (Elvis, Orkan, Licrown, Licord, Contact ve Oase) azot varlığında ve yokluğunda gösterdiği azot etkinliklerini tespit etmektir. Bu kapsamda uygulanan $100 \mathrm{mg} \mathrm{N} \mathrm{kg}^{-1}$ azotun kanola çeşitlerinin yaş ağırlık, kuru ağırlık, azot $(\mathrm{N})$ içeriği, nitrat azotu $\left(\mathrm{NO}^{3}-\mathrm{N}\right)$ içeriği, azot $(\mathrm{N})$ alımı, organik azot $(\mathrm{N})$ içeriği, asimilasyon etkinliği, azot etkinliği ve fizyolojik azot etkinliği belirlenmiştir. Azot uygulaması, kanola çeşitlerinin azot içeriğini, azot alımını ve organik azot içeriğini istatistiki olarak önemli düzeyde artırmıştır ( $\mathrm{p}<0,05)$. Azot etkinliği çeşitler arası farklılık göstermiştir. Ancak Elvis ve Licrown çeşitleri en etkin azot etkinliği gösteren çeşitler olmuştur. Çalışma sonucunda; azot etkinliği yönünden çeşit seçiminde birden çok özelliğin dikkate alınması gerektiği ortaya konulmuştur.

Anahtar Kelimeler: Kanola, azot etkinliği, azot kapsamı, asimilasyon oranı

\section{ABSTRACT}

The aim of this study is to determine the nitrogen activities of canola cultivars (Elvis, Orkan, Licrown, Licord, Contact and Oase) in the presence and absence of nitrogen. The wet weight, dry weight, nitrogen $(\mathrm{N})$ content, nitrate nitrogen $\left(\mathrm{NO}_{3}-\mathrm{N}\right)$ content, nitrogen $(\mathrm{N})$ uptake, organic nitrogen $(\mathrm{N})$ content, assimilation efficiency, nitrogen content of canola varieties of

Yüksek Lisans tezi çalışmasıdır.

Gönderilme Tarihi :

Kabul Tarihi
Sorumlu Yazar Yasemin UÇAR ucaryasemin2003@yahoo.com

iD 0000-0002-7840-6620

Ali İNAL inal@agri.ankara.edu.tr 0000-0003-4611-8613 Yazar 
100 mg N kg-1 nitrogen applied in this context. efficiency and physiological nitrogen efficiency were determined. Nitrogen application significantly increased nitrogen content, nitrogen uptake and organic nitrogen content of canola cultivars $(\mathrm{p}<0.05)$. Nitrogen efficiency differed between cultivars. However, Elvis and Licrown cultivars were the cultivars that showed the most effective nitrogen activity. In the results of working; It has been revealed that more than one feature should be taken into account in the selection of varieties in terms of nitrogen efficiency.

Key Words: Canola, Nitrogen efficiency, Nitrogen content, Assimilation rate

\section{GİRIŞ}

Kolza olarak bilinen kanola, yağ şalgamına benzeyen tek yıllık yazlık ve kışlık formları olan bir yağ bitkisidir. Brassica oleracea (Lahana) ve Brassica campestris (yağ şalgamı)'in melezlenmesi sonucunda kromozom sayılarının ikiye katlanmasıyla ortaya çıkan amphiploid bir bitkidir. Dünya yağlı tohum üretiminde soya ve palmden sonra üçüncü sırada yer almaktadır (Arıoğlu, Kolsarıcı, Göksu, Güllüoğlu, Arslan, Çalışkan, Söğüt, Kurt, Arslanoğlu, 2010).

Geleneksel kullanım açısından kanolayağı, deterjanlarda kayganlaştırıcı madde olarak kullanımının yanında, krem üretimi ile poliamid lifi, reçine ve bitkisel kökenli balmumu üretiminde de kullanılmaktadır (Anonim, 2000).

Kanola, bitkisel yağlar arasında doymuş yağ oranı en az olanıdır. Kanola yağı doymuş yağ asidi ve doymamış yağ asidi bakımından oldukça dengeli bir bileşime sahiptir (Arığlu vd., 2010). Bu özellikleri nedeniyle kanola yağı, omega 3 - omega 6 grubuna girerek kanda kolesterol dengesini düzenlemekte, trigliserit seviyesini düşürmekte ve kalp damar hastalıkları riskini azaltmaktadır. Kanola yağı, E vitamini (tokoferol) açısından zengin olup, hücreleri koruyucu ve yenileyici etkisi ve antioksidan etkisi yoluyla başta kanser olmak üzere çoğu hastalığa karşı önleyici ve koruyucu özelliğe sahiptir.

Dünya genelinde; ekiliş ve üretiminde artış eğilimi soya ile birlikte sadece kolza bitkisinde gözlenmiştir. Türkiye'de kolza ekiliş alanı 2001, 2002, 2003 ve 2004 yıllarında sirasiyla 290, 550, 650 ve 650 ha üretimi ise yine aynı yıllarda sırasıyla 650, 1500, 1000 ve 1000 ton olmuştur. Kolza, dünya yağlı tohum ekiliş alanı içerisinde 2004 yılına göre \%13'lük paya sahip iken Türkiye'de \%2'lik paya sahiptir (Anonymous, 2009). Türkiye'de kanola (kolza) üretimi son yıllarda özellikle Marmara bölgesinin Trakya yöresi başta olmak üzere Karadeniz, Ege ve Güneydoğu bölgelerinde de yaygınlaşmaya başlamıştır (Arığlu vd., 2010)

Yazlık ve kışlık varyetelerinin bulunması, birim alandan yüksek verim alınabilmesi ve tohum yağ oranının yüksek olması, ekiminden hasadına kadar bütün yetiştirme tekniğinin mekanizasyona uygun olması önemli bir yă̆ bitkisi olma özelliğini kazandırmaktadır (Kolsarıcı, Gürbüz, Arığlu, Çalışkan, Algan, 1990).

Azot, bitkide dal sayısı ve çiçek sayısı gibi büyüme parametrelerini etkileyerek ürünü artırır (Allen ve Morgan 1972; Taylor, Smith, Witson, 1991) ve daha hızlı büyümeye neden olarak vejetatif gelişmeyi, bitki boyunu, toplam bitki ağırlığını, yaprak alanı indeksini, kapsül ve tohum sayısını ve ağırlığını artırarak gelişimi etkiler (Allen ve Morgan, 1972). Holmes (1980) Azotlu gübre uygulama zamanı ve miktarının doğru seçilmesinin kanola üretim ve veriminde önemli oranda etkili olduğunu belirtmiştir.

Kanola azot gereksinimi yüksek olan bir bitkidir (Sarandón, Chamorro, Bezus, Giannibelli, 1993) ve $250 \mathrm{~kg}$ $\mathrm{da}^{-1}$ tane verimi için toprağın $20-25 \mathrm{~kg} \mathrm{da}^{-1} \mathrm{~N}$ içeriğine sahip olması gerekmektedir (Schjoerring, Bock, Gammelvind, Jensen, Mogensen, 1995).

Genel olarak, gübrelerin etkin kullanımı ürün artısında önemli bir faktördür. Ürünü azaltmadan kullanılan azotlu gübreyi azaltmak amaciyla azotu daha etkin kullanan ve metabolize eden çeşitlerin seçimi ıslahçıların temel çalışma konusunu oluşturmaktadır.

$\mathrm{Bu}$ çalışma; 6 kanola çeşidinin (Elvis, Orkan, Licrown, Licord, Contact ve Oase) azot etkinliklerinin karşılaştırılması amacıyla yürütülmüştür. 


\section{MATERYAL VE YÖNTEM}

\section{Toprağın Seçimi ve Fizikokimyasal Analizleri}

$\mathrm{Bu}$ çalışmada kullanılacak toprak örneği Ankara Üniversitesi Ziraat Fakültesi Toprak Bilimi ve Bitki Besleme Bölümü deneme alanından alınmıştır. Toprak 0-20 cm derinlikten alınıp, 4 mm' lik elekten geçirilmiştir (Kacar 2009). Aynı toprağın bir kısmı alınıp 2 mm'lik elekten geçirilmiştir. Elde edilen bu toprağın fizikokimyasal özellikleri belirlenmiştir. Deneme toprağının kil miktarı (\%29,28), kum miktarı $(\% 36,72)$, silt miktarı (\%34), tekstür sınıfı (Killi tın), kireç miktarı $\left(\mathrm{CaCO}_{3}, \% 6,35\right)$, toplam azot miktarı $(\% 0,096), \mathrm{pH}(7,73)$, organik madde miktarı (\%2), saturasyon ekstraktı $\left(0,5 \mathrm{dS} \mathrm{m}^{-1}\right)$, bitkiye yarayışlı $\mathrm{P}\left(4,35 \mathrm{mg} \mathrm{kg}^{-1}\right)$, ekstrakte edilebilir K $(523 \mathrm{mg}$ $\left.\mathrm{kg}^{-1}\right)$ ve saturasyon (\%67) olarak bulunmuştur.

\section{Sera Denemesinin Kurulması ve Yürütülmesi}

Sera denemesinde bitki materyali olarak kolza (kanola) (Brassica napus ssp. oleraceae L.)'nın Elvis, Orkan, Licrown, Licord, Contact ve Oase olmak üzere 6 çeșidi kullanılmıștır. Bitkilerin ekileceği 2,25 kg'llk toprak polietilen kaplı plastik saksılara doldurulmuştur. Bitkilerin ekimi başlamadan önce saksılara $100 \mathrm{mg} \mathrm{kg}^{-1} \mathrm{P}$ ve $125 \mathrm{mg} \mathrm{kg}^{-1} \mathrm{~K}\left(\mathrm{KH}_{2} \mathrm{PO}_{4}\right)$ uygulanmış ve toprak iyice karıştırılmıştır. Saksıların yarısına $\mathrm{N}$ uygulanmamış, diğer yarısına ise $100 \mathrm{mg} \mathrm{kg}^{-1}$ $\mathrm{N}\left[\left(\mathrm{NH}_{4}\right)_{2} \mathrm{SO}_{4}\right]$ iki seferde verilmiştir. Azotun yarısı ekimle birlikte uygulanmış ve toprak iyice karıştırılmıştır.
Azotun kalan yarısı ise bitkiler 6 gerçek yapraklı olduğunda sulama suyu ile verilmiştir. Deneme faktöriyel (6 çeşit ve 2 azot dozu) olup tesadüf parselleri deneme desenine göre 4 tekerrürlü olarak sera koşullarında yürütülmüştür. Bitkiler 7 haftalık gelişim süreci sonunda hasat edilmiş ve yaş ağırlıkları belirlenmiştir. Laboratuvara getirilen bitki örnekleri $65^{\circ} \mathrm{C}$ sıcaklığa ayarlı hava sirkülasyonlu kurutma dolabında değişmez ağırlığa ulaşıncaya değin kurutulup kuru ağırlıkları belirlenmiştir. Daha sonra çelik bıçaklı kahve öğütme değirmeninde öğütülerek kilitli poşetlerde koruma altına alınmıştır.

\section{Bitki Analizleri}

Büyüme evresini tamamlamış olan bitkiler toprak yüzeyine yakın yerinden kesilmiştir. Kesilen bitkiler temizlenmiş ve $65^{\circ} \mathrm{C}$ 'de kurutulmuştur. Bitkiler için ilk önce ögütülmüş ve daha sonra kuru yakma yöntemiyle analize hazır hale getirilmiştir. Analize hazır hale gelen bitkilerin içermiş oldukları toplam azot miktarı ve nitrat azotu Kjeldahl yöntemi ve Shimadzu model UV 1201 markalı spektrofotometre kullanılarak gerçekleştirilmiştir (Kacar ve İnal 2008). Kanola bitki çeşitlerinin azot alımı, organik azot içeriği, asimilasyon etkinliği ve azot etkinliğini belirlemek için kullanılan yöntem ve formüller Çizelge 1'de verilmiştir (İnal ve Güneş 1995; Hirel vd. 2007).

Çizelge 1. Bitki analizlerinde kullanılan yöntem ve formüller

\begin{tabular}{|c|c|}
\hline Analiz çeşitleri & Kullanılan yöntem veya formül \\
\hline Toplam azot $(\mathrm{N})$ tayini & Kjeldahl yöntemi \\
\hline Nitrat azotu $\left(\mathrm{NO}_{3}-\mathrm{N}\right)$ tayini & Shimadzu model UV 1201 spektrofotometre \\
\hline Azot $(\mathrm{N})$ alımı tayini & Azot $(\mathrm{N})$ alımı= Kuru ağırlık (g) x Bitki örneğinin toplam N içeriği (\%) x 10 \\
\hline Organik azot tayini & Organik azot = Bitki örneğinin toplam N içeriği (\%) - Bitki örneğinin $\mathrm{NO}_{3}-\mathrm{N}^{\prime} \mathrm{u}$ içeriği (\%) \\
\hline Asimilasyon etkinliği tayini & $\begin{array}{l}\text { Asimilasyon Etkinliği = (Bitki örneğinin } \mathrm{NO}_{3} \text {-N'u içeriği (\%) / Bitki örneğinin toplam N içeriği } \\
(\%)) \times 100\end{array}$ \\
\hline Azot etkinliği tayini & Azot Etkinliği = (Gübresizde kuru ağırlık (g) / Gübrelide kuru ağırlık (g)) x 100 \\
\hline Fizyolojik etkinliğin tayini & $\begin{array}{l}\text { Fizyolojik Etkinlik= (Gübrelide kuru ağırlık (mg) - Gübresizde kuru ağırlık (mg)) / (Gübrelide N } \\
\text { alımı (mg) - Gübresizde N alımı (mg)) }\end{array}$ \\
\hline
\end{tabular}




\section{İstatistik Analizler}

Araşıırma çeşit ve doz olmak üzere iki faktörlü deneme düzenine göre tasarlanmıştır. Bu sebeple verilerin analizinde iki yönlü varyans analizi tercih edilmiştir. Ayrıca kanola çeşitlerinde azot ve fizyolojik azot etkinliklerini karşılaştırmak için tek yönlü varyans analizi kullanılmıştır. $\mathrm{Bu}$ çalışma MINITAB paket programı kullanılarak gerçekleştirilmiştir. Grup ortalamaları arasındaki farkın önemlilik durumu ise MSTAT paket programı kullanılarak Duncan Çoklu Karşılaştırma Testi ile belirlenmiştir (Düzgüneş, 1963).

\section{BULGULAR}

Bu çalışmada 6 farklı kanola çeşidinin azot etkinliğinin tespiti için azot uygulaması yapılan ve yapılmayan çeşitlerin yaş ağırlık, kuru ağırlık, azot $(\mathrm{N})$ içeriği, nitrat azotu $\left(\mathrm{NO}_{3}-\mathrm{N}\right)$ içeriği, azot $(\mathrm{N})$ alımı, organik azot $(\mathrm{N})$ içeriği, asimilasyon etkinliği, azot etkinliği ve fizyolojik azot etkinliği belirlenmiştir.

\section{Yaş Ağırlık}

Azot uygulanmayan $\left(0 \mathrm{mg} \mathrm{N} \mathrm{kg}^{-1}\right)$ ve azot uygulanan (100 mg N kg ${ }^{-1}$ ) koşullarda yetiştirilen kanola çeşitlerinin yaş ağırlıkları belirlenmiş olup, Çizelge 2'de gösterilmiştir. Kanola çeşitlerinin yaş ağırlığına, hem çeşidinin hemde azotun etkili olduğu görülmüştür $(\mathrm{p}<0,01)$. Ayrıca çeşit ve azotun ortak etkisine bağlı olarak yaş ağırlı̆̆ında anlamlı bir farklılık gözlenmiştir $(\mathrm{p}<0,05)$.

Çizelge 2. Azot uygulanmayan ( $0 \mathrm{mg} \mathrm{N} \mathrm{kg-1)}$ ve azot uygulanan (100 mg N kg-1) koşullarda yetiştirilen kanola çeşitlerinin yaş ağırlı̆̆ı, g saksı-1

\begin{tabular}{|l|c|c|}
\hline & \multicolumn{2}{|c|}{ Yaş Ağırlık, g saksi ${ }^{-1}$} \\
\hline Çeşitler & $0 \mathrm{~m} \mathrm{~N} \mathrm{~kg}^{-1}$ & $100 \mathrm{mg} \mathrm{N} \mathrm{kg}^{-1}$ \\
\hline Elvis & $33.83 \mathrm{e}$ & $82.98 \mathrm{ab}$ \\
\hline Orkan & $32.48 \mathrm{e}$ & $84.55 \mathrm{a}$ \\
\hline Licrown & $30.25 \mathrm{ef}$ & $73.84 \mathrm{~d}$ \\
\hline Licord & $25.78 \mathrm{fg}$ & $77.84 \mathrm{~cd}$ \\
\hline
\end{tabular}

\begin{tabular}{|l|c|c|c|}
\hline Contact & $24.63 \mathrm{~g}$ & \multicolumn{2}{|c|}{$79.60 \mathrm{bc}$} \\
\hline Oase & $29.49 \mathrm{ef}$ & \multicolumn{2}{|c|}{$77.75 \mathrm{~cd}$} \\
\hline F değeri & Çeşit: 9.09 & Azot: 3343.69 & $\begin{array}{c}\text { Çeşit x Azot: } \\
3.48\end{array}$ \\
\hline P değeri & $0,002^{* *}$ & $0,004^{* *}$ & $0,035^{*}$ \\
\hline
\end{tabular}

${ }^{*} \mathrm{p}<0.05,{ }^{* *} \mathrm{p}<0.01$

Azot uygulanmayan koşullara göre azot uygulanan koşullarda, kanola çeşitlerinin yaş ağırlığındaki artışlar önemli olmuştur. Çeşitlerin azot uygulanan ve uygulanmayan koşullara verdikleri tepkiler farklı olmuştur. Azot uygulanmayan koşullarda Elvis ve Orkan çeşitlerinin yaş ağırlığı, Licord ve Contact çeşitlerinin yaş ağırlığından istatistiki olarak önemli oranda yüksek olurken, Contact çeşidinin yaş ağırlığı, Licord dışında diğer çeşitlerin yaş ağırlığından istatistiki olarak önemli derecede düşük olmuştur. Azot uygulanan koşullarda ise Elvis ve Orkan çeşitlerinin yaş ağırlığı, diğer çeşitlerin yaş ağırlığından istatistiki olarak önemli derecede yüksek olmuştur. Ayrıca Licrown çeşidi, Contact çeşidine göre daha düşük yaş ağırlığa sahip olmuştur.

\section{Kuru Ağırlık}

Azot uygulanmayan $\left(0 \mathrm{mg} \mathrm{N} \mathrm{kg}^{-1}\right)$ ve azot uygulanan (100 $\mathrm{mg} \mathrm{N} \mathrm{kg}^{-1}$ ) koşullarda yetiştirilen kanola çeşitlerinin kuru ağırlıkları belirlenmiş olup, Çizelge 3'de gösterilmiştir. Kanola çeşitlerinin kuru ağırlığına, hem çeşidinin hemde azotun etkili olduğu görülmüştür $(\mathrm{p}<0,01)$. Ayrıca çeşit ve azotun ortak etkisine bağlı olarak kuru ağırlığında anlamlı bir farklılık gözlenmiştir $(\mathrm{p}<0,01)$. Azot uygulanmayan koşullarda, kanola çeşitlerinin kuru ağırlıkları arasında farklılık görülmemiştir. Ancak azot uygulanan koşullarda ise Contact çeşidinin kuru ağırlığ 1 Oase, Elvis ve Licrown çeşitlerinin kuru ağırlıklarından yüksek olduğu görülmüştür. Elvis ve Licrown çeşitlerinin kuru ağırlıkları diğer çeşitlerin kuru ağırlığından belirgin ve önemli derecede düşük olmuştur. 
Çizelge 3. Azot uygulanmayan ve azot uygulanan koşullarda yetiştirilen kanola çeşitlerinin kuru ağırlığ 1

\begin{tabular}{|l|c|c|c|}
\hline & \multicolumn{2}{|c|}{ Kuru Ağırlık, g saksi ${ }^{-1}$} \\
\hline Çeşitler & $0 \mathrm{mg} \mathrm{N} \mathrm{kg}{ }^{-1}$ & \multicolumn{2}{|c|}{$100 \mathrm{mg} \mathrm{N} \mathrm{kg}^{-1}$} \\
\hline Elvis & $4,53 \mathrm{~d}$ & \multicolumn{2}{|c|}{$9,46 \mathrm{c}$} \\
\hline Orkan & $5,30 \mathrm{~d}$ & \multicolumn{2}{|c|}{$12,66 \mathrm{ab}$} \\
\hline Licrown & $4,42 \mathrm{~d}$ & \multicolumn{2}{|c|}{$8,63 \mathrm{c}$} \\
\hline Licord & $4,53 \mathrm{~d}$ & \multicolumn{2}{|c|}{$12,06 \mathrm{ab}$} \\
\hline Contact & $4,45 \mathrm{~d}$ & \multicolumn{2}{|c|}{$13,25 \mathrm{a}$} \\
\hline Oase & $5,01 \mathrm{~d}$ & \multicolumn{2}{|c|}{$11,75 \mathrm{~b}$} \\
\hline F değeri & Çeşit: 10.35 & $\begin{array}{c}\text { Azot: } \\
662.83\end{array}$ & $\begin{array}{c}\text { Çeşit x Azot: } \\
7.52\end{array}$ \\
\hline P değeri & $0,001^{* *}$ & $0,004^{* *}$ & $0,002^{* *}$ \\
\hline
\end{tabular}

${ }^{*} \mathrm{p}<0.05,{ }^{* *} \mathrm{p}<0.01$

\section{Azot (N) İçeriği}

Azot uygulanmayan $\left(0 \mathrm{mg} \mathrm{N} \mathrm{kg}^{-1}\right)$ ve azot uygulanan (100 mg N kg${ }^{-1}$ ) koşullarda yetiştirilen kanola çeşitlerinin azot içeriği belirlenmiş olup, Çizelge 4'de gösterilmiştir. Kanola çeşitlerinin azot içeriğine, hem çeşidinin hemde azotun etkili olduğu görülmüştür $(\mathrm{p}<0,01)$. Ancak çeşit ve azotun ortak etkisine bağlı olarak azot içeriğinde anlamlı bir farklılık gözlenmemiştir ( $p>0,05)$. Azot uygulanan çeşitlerde azot içeriğinin artışının yüksek olduğu görülmüştür. Azot uygulanmayan ve ugulanan koşullarda Elvis ve Licrown çeşidinin azot içeriği diğer çeşitlerin azot içeriğinden yüksek olduğu görülmüştür.

Çizelge 4. Azot uygulanmayan ve azot uygulanan koşullarda yetiştirilen kanola çeşitlerinin azot içeriği

\begin{tabular}{|l|c|c|c|}
\hline & \multicolumn{2}{|c|}{ Azot içeriği (\%) } & \\
\hline Çeşitler & $\begin{array}{c}0 \mathrm{mg} \mathrm{N} \\
\mathrm{kg}^{-1}\end{array}$ & $100 \mathrm{mg} \mathrm{N} \mathrm{kg}^{-1}$ & Ortalama \\
\hline Elvis & 1,48 & 2,08 & $1.78 \mathrm{a}$ \\
\hline Orkan & 1,07 & 1,28 & $1.28 \mathrm{~b}$ \\
\hline Licrown & 1,5 & 1,93 & $1.93 \mathrm{a}$ \\
\hline Licord & 1,03 & 1,26 & $1.26 \mathrm{~b}$ \\
\hline
\end{tabular}

\begin{tabular}{|l|c|c|c|}
\hline Contact & 1,00 & 1,22 & $1.22 \mathrm{~b}$ \\
\hline Oase & 0,99 & 1,28 & $1.28 \mathrm{~b}$ \\
\hline Ortalama & 1.18 & 1.74 & \\
\hline F değeri & $\begin{array}{c}\text { Çeşit: } \\
31.69\end{array}$ & Azot: 151.84 & Çeşit x Azot: 2.19 \\
\hline P değeri & $0,001^{* *}$ & $0,000^{* *}$ & 0,073 \\
\hline
\end{tabular}

${ }^{*} \mathrm{p}<0.05,{ }^{* *} \mathrm{p}<0.01$

\section{Nitrat azotu $\left(\mathrm{NO}_{3}-\mathrm{N}\right) \dot{\mathrm{I}}$ çeriği}

Azot uygulanmayan $\left(0 \mathrm{mg} \mathrm{N} \mathrm{kg}^{-1}\right)$ ve azot uygulanan (100 $\mathrm{mg} \mathrm{N} \mathrm{kg}^{-1}$ ) koşullarda yetiştirilen kanola çeşitlerinin nitrit azot içeriği belirlenmiş olup, Çizelge 5 'de gösterilmiştir. Kanola çeşitlerinin nitrit azot içeriğine, hem çeşidinin hemde azotun etkili olduğu görülmüştür $(\mathrm{p}<0,01)$. Ayrıca çeşit ve azotun ortak etkisine bağlı olarak nitrit azot içeriğinde anlamlı bir farklılık gözlenmiştir $(\mathrm{p}<0,01)$. Azot uygulanmayan koşullarda, kanola çeşitlerinin nitrit azot içerikleri arasında farklılık görülmemiştir. Ancak azot uygulanan koşullarda ise Elvis ve Licrown çeşidinin nitrit azot içeriği diğer çeşitlerin azot içeriğinden yüksek olduğu görülmüştür.

Çizelge 5. Azot uygulanmayan ve azot uygulanan koşullarda yetiştirilen kanola çeşitlerinin nitrit azot içeriği , mg kg-1

\begin{tabular}{|c|c|c|c|}
\hline & \multicolumn{3}{|c|}{$\begin{array}{l}\text { Nitrit azot içeriği, } \\
\left(\mathrm{NO}_{3}-\mathrm{N}\right), \mathrm{mg} \mathrm{kg}^{-1}\end{array}$} \\
\hline Çeşitler & $0 \mathrm{mg} \mathrm{N} \mathrm{kg}^{-1}$ & \multicolumn{2}{|c|}{$100 \mathrm{mg} \mathrm{N} \mathrm{kg}^{-1}$} \\
\hline Elvis & $403 c$ & \multicolumn{2}{|c|}{$1201 \mathrm{~b}$} \\
\hline Orkan & $382 \mathrm{c}$ & \multicolumn{2}{|c|}{$518 \mathrm{c}$} \\
\hline Licrown & $564 c$ & \multicolumn{2}{|c|}{ 1741a } \\
\hline Licord & $374 \mathrm{c}$ & \multicolumn{2}{|c|}{$431 \mathrm{c}$} \\
\hline Contact & $385 c$ & \multicolumn{2}{|c|}{$522 c$} \\
\hline Oase & $358 \mathrm{c}$ & \multicolumn{2}{|c|}{$466 c$} \\
\hline F değeri & Çeşit: 12.68 & Azot: 33.19 & $\begin{array}{l}\text { Çeşit x Azot: } \\
7.55\end{array}$ \\
\hline P değeri & $0,003^{* *}$ & $0,002^{* *}$ & $0,000^{* *}$ \\
\hline
\end{tabular}




\section{$\operatorname{Azot}(\mathrm{N})$ Alımı}

Azot uygulanmayan $\left(0 \mathrm{mg} \mathrm{N} \mathrm{kg}^{-1}\right)$ ve azot uygulanan (100 mg N kg-1) koşullarda yetiştirilen kanola çeşitlerinin azot alımları belirlenmiş olup, Çizelge 6'da gösterilmiştir. Kanola çeşitlerinin azot alımına, hem çeşidinin hemde azotun etkili olduğu görülmüştür $(p<0,01)$. Ancak çeşit ve azotun ortak etkisine bağlı olarak azot alınımında anlamlı bir farklılık gözlenmemiştir ( $>>0,05)$. Azot uygulanan çeşitlerde azot alımlarının artışının yüksek olduğu görülmüştür. Azot uygulanmayan ve ugulanan koşullarda Elvis ve Licrown çeşidinin azot alımı diğer çeşitlerin azot alımından yüksek olduğu görülmüştür.

Çizelge 6. Azot uygulanmayan ve azot uygulanan koşullarda yetiştirilen kanola çeşitlerinin azot alımı miktarı

\begin{tabular}{|l|c|c|c|}
\hline & \multicolumn{2}{|c|}{ Azot alımı, mg saksi ${ }^{-1}$} & \\
\hline Çeşitler & $\begin{array}{c}0 \mathrm{mg} \mathrm{N} \\
\mathrm{kg}^{-1}\end{array}$ & $100 \mathrm{mg} \mathrm{N} \mathrm{kg}^{-1}$ & Ortalama \\
\hline Elvis & 66,80 & 196,33 & $131.57 \mathrm{a}$ \\
\hline Orkan & 56,65 & 187,19 & $121.92 \mathrm{~b}$ \\
\hline Licrown & 65,88 & 202,84 & $134.36 \mathrm{a}$ \\
\hline Licord & 46,37 & 177,41 & $111.89 \mathrm{~b}$ \\
\hline Contact & 44,15 & 188,99 & $116.57 \mathrm{~b}$ \\
\hline Oase & 49,63 & 183,35 & $116.49 \mathrm{~b}$ \\
\hline Ortalama & 54.91 & 189.35 & \\
\hline F değeri & $\begin{array}{c}\text { Çeşit: } \\
7.74\end{array}$ & Azot: 2581.21 & Çeşit x Azot: 0,79 \\
\hline P değeri & $0,002^{* *}$ & $0,001^{* *}$ & 0,058 \\
\hline * p $<0.05, * * \mathrm{p}<0.01$ & & \\
\hline
\end{tabular}

\section{Organik Azot (N) İçeriği}

Azot uygulanmayan $\left(0 \mathrm{mg} \mathrm{N} \mathrm{kg}^{-1}\right)$ ve azot uygulanan (100 mg N kg-1) koşullarda yetiştirilen kanola çeşitlerinin organik azot içeriği yüzdeleri belirlenmiş olup, Çizelge 7’de gösterilmiştir. Kanola çeşitlerinin organik azot içeriğine, hem çeşidinin hemde azotun etkili olduğu görülmüştür $(\mathrm{p}<0,01)$. Ancak çeşit ve azotun ortak etkisine bağlı olarak organik azot içeriğinde anlamlı bir farklılık gözlenmemiştir ( $p>0,05)$. Azot uygulanan çeşitlerde organik azot içeriği artışının yüksek olduğu görülmüştür. Azot uygulanmayan ve ugulanan koşullarda Elvis ve Licrown çeşidinin organik azot içeriği diğer çeşitlerin organik azot içeriğinden yüksek olduğu görülmüştür $(\mathrm{p}<0,05)$.

Çizelge 7. Azot uygulanmayan ve azot uygulanan koşullarda yetiştirilen kanola çeşitlerinin organik azot içeriği yüzdesi

\begin{tabular}{|l|c|c|c|}
\hline & \multicolumn{2}{|c|}{ Organik azot içeriği yüzdesi } & \\
\hline Çeşitler & $\begin{array}{c}0 \mathrm{mg} \mathrm{N} \\
\mathrm{kg}^{-1}\end{array}$ & $100 \mathrm{mg} \mathrm{N} \mathrm{kg}^{-1}$ & Ortalama \\
\hline Elvis & $1,44^{\mathrm{a}}$ & $1,96^{\mathrm{b}}$ & $1.70 \mathrm{a}$ \\
\hline Orkan & $1,03^{\mathrm{c}}$ & $1,44^{\mathrm{d}}$ & $1.24 \mathrm{~b}$ \\
\hline Licrown & $1,45^{\mathrm{e}}$ & $2,19^{\mathrm{f}}$ & $1.82 \mathrm{a}$ \\
\hline Licord & $0,99^{\mathrm{g}}$ & $1,45^{\mathrm{h}}$ & $1.22 \mathrm{~b}$ \\
\hline Contact & $0,96^{\mathrm{i}}$ & $1,38^{\mathrm{i}}$ & $1.17 \mathrm{~b}$ \\
\hline Oase & $0,96^{\mathrm{j}}$ & $1,52^{\mathrm{k}}$ & $1.24 \mathrm{~b}$ \\
\hline Ortalama & 1.14 & 1.66 & \\
\hline F değeri & Çeşit: & Azot: 142.24 & Çeşit x Azot: 1.31 \\
\hline P değeri & $0,001^{* *}$ & $0,000^{* *}$ & 0,078 \\
\hline
\end{tabular}

${ }^{*} \mathrm{p}<0.05,{ }^{* *} \mathrm{p}<0.01$

\section{Asimilasyon Etkinliği}

Azot uygulanmayan $\left(0 \mathrm{mg} \mathrm{N} \mathrm{kg}^{-1}\right)$ ve azot uygulanan (100 mg N kg $\left.{ }^{-1}\right)$ koşullarda yetiştirilen kanola çeşitlerinin asimilasyon etkinliği belirlenmiş olup, Çizelge 8'de gösterilmiştir. Kanola çeşitlerinin asimilasyon etkinliğine, hem çeşidinin hemde azotun etkili olduğu görülmüştür $(\mathrm{p}<0,05)$. Ayrıca çeşit ve azotun ortak etkisine bağlı olarak asimilasyon etkinliğinde anlamlı bir farklılık gözlenmiştir $(\mathrm{p}<0,01)$. Azot uygulanan Elvis ve Licrown çeşitlerinde asimilasyon etkinliklerinin artışının yüksek olduğu görülmüştür. Azot uygulanmayan koşullarda, kanola çeşitlerinin ortalama asimilasyon etkinlikleri arasındaki fark önemli bulunmazken, azot uygulanan koşullarda, Elvis ve Licrown çeşitlerinin asimilasyon etkinliği diğer çeşitlerin asimilasyon etkinliğinden yüksek olduğu görülmüştür. 
Çizelge 8. Azot uygulanmayan ve azot uygulanan koşullarda yetiştirilen kanola çeşitlerinin asimilasyon etkinliği

\begin{tabular}{|l|c|c|c|}
\hline & \multicolumn{2}{|c|}{ Asimilasyon etkinliği } \\
\hline Çeşitler & $0 \mathrm{mg} \mathrm{N} \mathrm{kg}^{-1}$ & \multicolumn{2}{|c|}{$100 \mathrm{mg} \mathrm{N} \mathrm{kg}^{-1}$} \\
\hline Elvis & $2,74 \mathrm{~b}$ & \multicolumn{2}{|c|}{$5,79 \mathrm{a}$} \\
\hline Orkan & $3,62 \mathrm{~b}$ & $3,45 \mathrm{~b}$ \\
\hline Licrown & $3,80 \mathrm{~b}$ & & \multicolumn{2}{|c|}{$7,23 \mathrm{a}$} \\
\hline Licord & $3,69 \mathrm{~b}$ & $2,91 \mathrm{~b}$ \\
\hline Contact & $3,93 \mathrm{~b}$ & $3,74 \mathrm{~b}$ \\
\hline Oase & $3,60 \mathrm{~b}$ & $2,99 \mathrm{~b}$ \\
\hline F değeri & Çeşit: 4.80 & Azot: 6.20 & Çeşit x Azot: 6.18 \\
\hline P değeri & $0,001^{* *}$ & $0,029^{*}$ & $0,000^{* *}$ \\
\hline
\end{tabular}

${ }^{*} \mathrm{p}<0.05,{ }^{* *} \mathrm{p}<0.01$

\section{Azot Etkinliği ve Fizyolojik Azot etkinliği}

Kanola çeşitlerinin azot etkinlikleri ve fizyolojik azot etkinlikleri belirlenmiş olup Çizelge 9'da gösterilmiştir. Kanola çeşitlerinin hem azot etkinlikleri hem de fizyolojik azot etkinlikleri arasında farklılık görülmüştür $(\mathrm{p}<0,01)$. Azot etkinlikleri değerlendirildiğinde Elvis ve Licrown çeşitlerinin azot etkinliklerinin diğer çeşitlerin

azot etkinliklerinden önemli derecede yüksek olduğu görülmüştür. Kanola çeşitlerinin fizyolojik azot etkinlikleri değerlendirildiğinde Elvis ve Licrown çeşitlerinin azot etkinliklerinin diğer çeşitlerin azot etkinliklerinden önemli derecede düşük olduğu görülmüştür.

Çizelge 9. Kanola çeşitlerinin azot ve fizyolojik azot etkinliği

\begin{tabular}{|l|c|c|c|c|c|c|}
\hline Çeşitler & Azot etkinliği & F değeri & P değeri & Fizyolojik azot etkinliği & F değeri & P değeri \\
\hline Elvis & $47,99 \mathrm{ab}$ & & & $38,06 \mathrm{~b}$ & & \\
Orkan & $42,23 \mathrm{bc}$ & & & $56,26 \mathrm{a}$ & & \\
Licrown & $51,10 \mathrm{a}$ & & & $31,05 \mathrm{~b}$ & & \\
Licord & $37,83 \mathrm{~cd}$ & 7,44 & $0,001^{* *}$ & $57,87 \mathrm{a}$ & $0,005^{* *}$ \\
Contact & $33,65 \mathrm{~d}$ & & & $61,38 \mathrm{a}$ & & \\
Oase & $42,80 \mathrm{bc}$ & & & $50,32 \mathrm{a}$ & & \\
\hline
\end{tabular}

${ }^{*} \mathrm{p}<0.05,{ }^{* *} \mathrm{p}<0.01$

\section{TARTIŞMA ve SONUÇ}

Dünya da giderek artan yağ ihtiyacına karşın, ekim alanları sınırlı kalmaktadır. Bu sebeple de yağ ihtiyacını karşılayabilmenin tek çözümü ürün ve kalite artısııın sağlanması için çeşitli çözümler geliştirmektedir. Günümüzde yăg bitkilerinin yetiştirilmesinde azotlu gübreler kullanılmaktadır. Ancak kullanılan gübreler hem maliyetli hem de çevre üzerinde olumsuz etkileri mevcuttur. 
$\mathrm{Bu}$ çalışma gübrelerin kullanımını sınırlandıracak alternatif çözümler geliştirmek için yapılmıştır. Bu çalışmada, önemli bir yağ bitkisi olan kanola bitkisinin farklı çeşitlerinin azot etkinliklerinin tespit edilmesi amaçlanmışır. Bu yapılan çalışmayla gerçekleştirilmek istenen, azot kullanım etkinliği yüksek olan kanola çeşidini seçilip yetiştirilmesidir. Bu sayede artan gübre maliyetlerinin düşürülmesi ve gübrenin çevre üzerindeki etkilerinin azaltılması amaçlanmaktadır.

$\mathrm{Bu}$ çalışmada 6 farklı kanola bitki çeşidinin azot etkinliğinin tespiti için azot uygulaması yapılan ve yapılmayan çeşitlerin yaş ağırlık, kuru ağırlık, azot (N) içeriği, nitrat azotu $\left(\mathrm{NO}_{3}-\mathrm{N}\right)$ içeriği, azot $(\mathrm{N})$ alımı, organik azot $(\mathrm{N})$ içeriği, asimilasyon etkinliği, azot etkinliği ve fizyolojik azot etkinliği belirlenmiştir.

Çalışmada kanola çeşitlerine azot uygulaması ile Elvis ve Orkan çeşitlerinde diğer çeşitlere göre yüksek yaş ağırlık elde edilmiştir (Çizelge 2), Ayrıca kanola çeşitlerine azot uygulaması sonucu Contact, Licord ve Orkan çeşitlerinde daha yüksek kuru ağırlık elde edilmiştir (Çizelge 3). Yaş ve kuru ağırlık artışındaki sonuçların diğer yapılan çalışmalar ile benzerlik gösterdiği söylenebilir. Özellikle kanola bitkisi üzerine gerçekleştirilen bir çalışmada azot alımında etkin olan çeşitlerin daha fazla biyokütle oluşturduğu ve sürgünlerinde bulunan azot içeriğinin düşük olduğu gösterilmiştir (Svečnjak ve Rengel 2006a). Başka bir çalışmada ise alınan azotun çiçeklenme öncesindeki dönem ile bitki büyümesinin ilişkili olduğu bildirilmiştir (Yau ve Thurling 1987). Aynı araştırmacı tarafından azot etkinliği yüksek olan bitkilerin kalıtımsal rolününde önemli olduğu vurgulamıştır. Ladha vd. (1998)'e göre azot uygulandı̆̆ında yüksek verim veren çeşitler yüksek azot etkinliği olan, düşük verim veren çeşitler ise düşük azot etkinliği olanlar olarak kabul edildiğini bildirmiştir.

Bu çalışmada, azot uygulamasına bağlı olarak kanola çeşitlerinde azot içeriği ve azot alımı artmıştır (Çizelge 4). Özellikle kanolanın Elvis ve Licrown çeşitlerinde diğer çeşitlere göre daha yüksek olmuştur. Benzer sonuçlar Chamorro vd. (2002) ve Svečnjak ve Rengel (2006b) tarafından da bildirilmiştir. Azot uygulanan ve uygulanmayan koşulların ortalaması olarak kanola çeşitlerinin azot alımı arasında yaklaşık 3.5 katlık bir fark gözlenmiştir. 20 buğday çeşidinde yaptığı çalışmasında, azot alımının azotlu ve azot uygulanmayan koşullarda 1.41.5 kat fark gösterdiğini belirtmişlerdir. Dordas ve Sioulas (2009) azot alımında, biriktirilmesinde ve azotun çeşitli organlardaki dağılımında çeşitler arası fark gözlendiğini belirtmiştir. Azot etkinliği yüksek olan Elvis ve Licrown çeşitlerinin, çeşitler ortalaması olarak azot alımı da yüksek olmuştur. Bu iki çeşidin azot uygulanan koşullarda nitrik azot içeriği ile organik azot içeriği yüksek olurken çeşitler ortalaması olarak toplam azot içeriği de yüksek olmuştur (Çizelge 5).

Çalışmamızda kanola çeşitlerinin asimilasyon etkinliği yüksek olanlar Licrown ve Elvis ve asimilasyon etkinliği düşük olanlar Oase, Orkan, Licord ve Contact çeşitleri olduğu görülmüştür (Çizelge 8). Çalışmadaki toplam azot, nitrik azot ve organik azot içerikleri ile benzer sonuçlar alındığı görülmüştür.

Çizelge 9'da görüldüğü üzere fizyolojik azot etkinliği ile azot etkinliği değerlerinin birbirinin tersi olduğu görülmüştür. Balint ve Rengel (2008)'e göre fizyolojik azot etkinliğini, alınan azotun organik maddeye dönüştürülme indeksi olduğundan bahsetmiştir. Bu nedenle de azot etkinliği ile fizyolojik azot etkinliği arasında ters ilişki olmasının doğal olduğunu açıklamıştır. Bu çalışmada elde edilen bilgilerin bilinen literatür bulguları ile uyumlu olduğu görülmüştür.

Bazı çalışmalarda kanolada azot etkinliğin yağ verimi açısından değerlendirilmesi gerektiğine dair görüşler vardır. Ancak bizim çalışmamızda vejetatif dönemde azot etkinliği değerlendirilmiştir. Balint ve Rengel (2008) azot içeriğinin vegatatif ve generatif donemdeki farklılıklarını incelemiştir. $\mathrm{Bu}$ çalışmada generatif dönemin uygun olduğunu öne sürmüştür. Ancak Gan vd. (2010) kolza bitkisinin toprak üstü aksamının azot içeriğinin fide döneminden çiçeklenme dönemine kadar arttığını sonra hasat dönemine kadar değişmeden kaldığını belirtmiştir. Bu durum, vejetatif dönemde alınan azotun önemini göstermektedir.

Ahmad vd. (1999) nitrat redüktaz aktivitesinin ortamdaki yarayışlı azot miktarından etkilendiğini 
belirtmişlerdir. Traore ve Maranville (1999) tane sorgum genotiplerinin azot dozuna bağlı olarak nitrat redüktaz aktivitesi yönünden fark göstermediğini, nitrat redüktaz aktivitesinin azot birikimi ve kullanım etkinliğini sınırlayıcı bir faktör rölü oynamadığını belirtmişlerdir. Elvis ve Licrown kanola çeşitlerinin azot uygulanan koşullarda nitrik azot içeriğinin yüksek olması bu çeşitlerin nitrat redüktaz enzim aktivitesi durumundan çok azot içeriği ve azot alımının yüksek olmasıyla açıklanabilir. Ancak benzer koşullarda yetiştirilen kanola çeşitlerinin nitrat içeriklerinde potansiyel farklılığı işaret eden herhangi bir bulgu mevcut değildir.

Sonuç olarak çalışmada kullanılan kanola bitkisine uygulanan azot konsantrasyonu sonucu çeşitlerdeki kuru ve yaş madde miktarlarında, azot konsantrasyonunda, azot alınımında, asimilasyonda çeşitli değişimleri gözlenmiştir. $\mathrm{Bu}$ değişimler sonucu olarak da kanola çeşitleri farklı azot etkinlikleri göstermişlerdir. Bu durum azotlu gübrelerin kullanılması ve çevre kirliliğinin önlenmesi açısından çeşit seçiminin potansiyel bir öneme sahip olduğunu göstermektedir. $\mathrm{Bu}$ çalışmadan elde edilen sonuçların çeşit sayısı ve incelenen parametreler de artırılarak tarla koşullarında araştırılması gerekmekte olduğu düşünülmektedir.

\section{Açıklama}

Bu yayın yazarın Prof. Dr. Ali İNAL’ın danışmanlığında yürütülen Yüksek Lisans Tezinden üretilmiştir. Çalışmanın yürütülmesi ve sonuçların yazılması esnasında araştırma ve yayın etiğine uyulmuştur. Herhangi bir "Çıkar Çatışması" bulunmamaktadır.

\section{KAYNAKLAR}

Ahmad, A., Abraham, G. and Abdin, M.Z. 1999. Physiological investigation of the impact of nitrogen and sulphur application on seed and oil yield of rapeseed (Brassica campestris L.) and mustard (Brassica juncea L. Czern. And Coss) genotypes. Journal of Agronomy and Crop Science, 183, 19-25.

Allen, E.J., Morgan, D.G. (1972). A Quantitative Analysis of the Effect of Nitrogen on the Growth, Development and Yield of Oilseed Rape. J. Agri. Sci., Cambridge, $78,315-324$

Anonim, (2000). Türkiye İstatistik Yıllığı T.C. Başbakanlık Devlet İstatistikleri Ens. Yıllığı Ankara.

Anonymous, (2009). FAO Production Yearbook. The State of Food and Agriculture Organization of United Nations, Rome.

Arıoğlu, H., Kolsarıcı Ö., Göksu, A.T., Güllüoğlu, L., Arslan ,M., Çalışkan, S., Söğüt, T., Kurt, C., Arslanoğlu, F. (2010). Yağ Bitkileri Üretiminin Artırılması Olanakları. Türkiye Ziraat Mühendisliği VII. Teknik Kongresi. Bildiriler Kitabı I:361-376. 11-15 Ocak, Ankara.

Balint, T. and Rengel, Z. 2008. Nitrogen efficiency of canola genotypes varies between vegetative stage and grain maturity. Euphytica, 164, 421-432.

Chamorro, AM, Tamagno, L.N., Bezus, R. and Sarandón, S.J. 2002. Nitrogen accumulation, partition, and nitrogen-use efficiency in canola under different nitrogen availabilities. Communication in Soil Science and Plant Analysis, 33(3- 4), 493-504.

Düzgüneş, O. (1963). Bilimsel Araştırmalarda İstatistik Prensipleri ve Metotları. E.Ü. Matbaası, İzmir.

Dordas, C. and Sioulas, C. 2009. Dry matter and nitrogen accumulation, partitioning, and retranslocation in safflower (Carthamus tinctorius L.) as affected by nitrogen fertilization. Field Crops Res., 110, 35-43.

Gan, Y., Campbell, C.A., Janzen, H.H., Lemke, R.L., Basnyat, P. and McDonald, C.L. 2010. Nitrogen accumulation in plant tissues and roots and $\mathrm{N}$ mineralization under oilseeds, pulses, and spring wheat. Plant Soil, 332: 451-461.

Hirel, B., Gouis, J.L., Ney, B., Gallais, A. (2007). The Challenge of İmproving Nitrogen use Efficiency in Crop Plants: Towards a More Central Role for Genetic Variability and Quantitative Genetics Within İntegrated Approaches. Journal of Experimental Botany, 58, 2369-2387.

Holmes, M.R.J. (1980). Nutrient of Oil Seed Rape Crop. Applied Sci. Pub. Barking Essex, UK.

İnal, A., Güneş, A. (1995). Effects of Nitrogenous 
Fertilization on Yield and Nitrate Accumulation in Sugarbeet. A. Ü. Ziraat Fak. Tarım Bilimleri Dergisi, $1(1), 27-30$.

Kaçar, B. (2009). Toprak Analizleri (Genişletilmiş 2. Baskı). Nobel Yayın No: 1387, Fen Bilimleri, 90, Nobel Bilim ve Araşıırma Merkezi Yayın No: 44, Ankara.

Kaçar, B., İnal, A. (2008). Bitki Analizleri. Nobel Yayın No: 1241, Fen Bilimleri, 63.. Nobel Yayın Dağıtım Ltd. Şti. Ankara, s. 892.

Kolsarıc1, Ö., Gürbüz, B., Arıŏlu, H., Çalışkan, C., Algan, N. (1990). Türkiye'de Yağ Bitkileri Üretimi ve Sorunları. Türkiye Ziraat Mühendisliği, 3.Teknik Kongresi, 8- 12 Ocak, Ankara.

Ladha, J.K., Kirk, G.J.D., Bennett, J., Peng, S., Reddy, C.K., Reddy, P.M. and Singh, U. 1998. Opportunities for increased nitrogen use efficiency from improved lowland rice germplasm. Field Crop. Res., 56: 41-71.

Sarandón, S.J., Chamorro, A.M., Bezus, R., Giannibelli, M.C. (1993). Respuesta De La Colza (Brassica napus L. var. oleifera) A La Fertilización Nitrogenada Efecto Sobre La Producción De Biomasa, Rendimiento En Semilla Y Sus Componentes. Rev. Fac. Agron., La Plata, 69, 63-67.

Schjoerring, J.K., Bock, J.G.H., Gammelvind, L., Jensen, C.R., Mogensen, V.O. (1995). Nitrogen Incorporation and Remobilization in Different Shoot Components of Field-Grown Winter Canola (Brassica napus L.) as Affected by Rate of Nitrogen Application and İrrigation. Plant Soil, 177, 255-264.

Svečnjak, Z. and Rengel, Z. 2006a. Nitrogen utilization efficiency in canola cultivars at grain harvest. Plant and Soil, 283, 299-307.

Svečnjak, Z. and Rengel, Z. 2006b. Canola cultivars differ in nitrogen utilization efficiency at vegetative stage. Field Crops Research, 97, 221-226.

Yau, S.K. and Thurling, N. 1987. Variation in nitrogen response among spring rape (Brassica napus) cultivars and its relationship to nitrogen uptake and utilization. Field Crops Res., 16, 139-155. 